menstruation, I hope to record in the future; but the case, which for want of better explanation, I regard as premature senility, seems to merit a separate description.

One point is interesting. We used to be taught that menstruation and ovulation were necessarily coincident, and indeed, interdependent. This view is now discarded. Heape of Cambridge, in his interesting study of menstruation in monkeys, has done much to destroy its vitality. In my patient ovulation apparently continues, though menstruation has ceased.

Dr. Percy Boulton, in the British Medical Journal vol. ii, 1872, mentions two cases of atrophy of uterus after pregnancy; and refers to Dr. Whitehead's case, which was supposed to be a case of absence of uterus following pregnancy. Mr. Lawson Tait, however, thought that Dr. Whitehead had in reality punctured the fundus uteri, "that the sound was free in the peritoneal cavity."

We are all familiar with cases in which amenorrhoea has followed upon a great shock; in all instances that have come under my notice, recovery has taken place in some months, generally without any local treatment; but I am not aware of any recorded case of permanent amenorrhoea and complete atrophy following directly upon a nervous shock.

It is obviously impossible to prove positively that ovulation persisted here; to prove it to demonstration, it would be necessary that the woman should have become pregnant, or that an ovum should have been discovered in the uterus or Fallopian tube; but it would appear from the occasional swelling of the breasts and general sense of pelvic discomfort that ovulation was still going on. Cases are well known in which, with congenital absence of uterus or infantile uterus, there has been dysmenorrhoea severe enough to necessitate oöphorectomy, which has cured the pain. There are enough instances in which pregnancy has occurred before menstruation to show that ovulation and menstruation are certainly not synchronous, and not necessarily coincident. Again, though amenorrhoea generally accompanies lactation, yet plenty of cases are on record of fertilization taking place during the amenorrhoea of lactation-a clear proof that ovulation continues.

No one, I suppose, doubts the very close and intimate connexion between these two phenomena; but the general tendency of modern views is towards the belief that they are under separate influences, having independent cycles. Happening in many cases, however, to fall together, it presents the appearance of consequent coincidence. The late $\mathrm{Mr}$. Lawson Tait in 28 coeliotomies found in 3 only indications of a ripe follicle. To those not particularly interested, and to the casual observer, when a blood-stained swelling is seen on the ovary it is at once assumed that it is a corpus luteum, or at any rate, a ripe follicle; but this is not necessarily so, for a careful microscopical examination has revealed in many instances the fact that they are atrophied follicles; and in regard to the recent discussion at the Obstetrical Society on ovarian pregnancy, it is of primary importance that these should all be most carefully examined.

In the Obstetrical Society'd Transactions, 1898 , vol. xl, page 165, Mr. Heape of Cambridge deals with the question of ovulation and menstruation in monkeys. He finds that the Macacus rhesus, though menstruating regularly, yet only breeds at certain seasons (about October). Again, in Queensland certain native women, whilst menstruating regularly, only breed at certain seasons; and I believe there is evidence to show that even in civilized countries certain women, though menstruating regularly, only have a portion of the year in which they become fertilized.

In operating on 42 monkeys (Semnopithecus entellus), all menstruating, he found no corpus luteum. In 22 Macacus rhesus, I4 menstruating, 8 not, be found no sign in either ovary. In 17 rhesus he found during menstruation signs of a corpus luteum in 3 only, and of these 3 only I recent.

At Olympia, when Barnum and Bailey's hippodrome was here three years ago, I studied the menstruation of the famous chimpanzee Johannah - she menstruated every fourth Wednesday for three months that I watched her. During the six years the keeper had been with her he told me she only showed signs of suffering the approach of a male ape during the months of September and October, though she menstruated with the utmost regularity.
In three operations of abdominal hysterectomy on menstruating females of Macacus sinicus there was no indication of any ripe follicle in either ovary to the naked eye, though I carefully looked for them.

I have recorded this case, because it is at least unusual, and if, as I believe to be the case; though I cannot bring absolute proof, ovulation has continued after menstruation has ceased, then it may be regarded as a pebble thrown upon the heap of evidence in favour of the view that ovulation and menstruation are not coincident.

\section{CASE OF INVERSION OF THE UTERUS.}

\section{By CECIL GRANTLEY HOYSTED, L.R.C.P.,} L.R.C.S.EDIN., L.S.A.LOND. Swanley.

Following the cases reported in the British Madical JoURnal (November gth, 1901, p. 1408, and December 28th, p. 1865), and occurring at a period when the midwives question is occupying our minds very seriously, and moreover, in a district which has recently been brought into notoriety by a correspondence in the JodRNAI, which has had bearing on the midwives question, the following case may present some interest.

An urgent message was sent to me on December $215 t$, roor, in the words something had gone wrong.

On arrival at the house. I found the patient, a multipara, aged 33 , in a tate of collapse the case being one of complete inversion of the uterus. The midwife stated that she was pressing hard on the abdomen to "push out the afterbirth," adding at the same time "she didn't pull the cord a bit," in a manner which led one to suspect that her conscience pricked her, "when it all came out."

Condition on Examination. - The woman was blanched, cold, clammy, and almost pulseless : the respirations were shallow and sighing, and she had that anxions ashy grey appearance which so often heralds death. There was a large swelling the size of a very large cocoanut, protrudin from the vulva having at first sight the appearance of an enormous pla centa. The first impression was that a large fibroid had been expelled with the placenta adherent, but on abdominal palpation no fundus uter could be felt in the hypogastrium thus enabling one to form the diagnosis of complete inversion of the uterus.

The treatment of the case was commenced by quickly "peeling" the placenta from the fundus. The separation took place easily, but was followed by profuse haemorrhage from several points. This was controlled by pour towels dipped in hot water. The woman's condition being so bad attempted reduction immediately, but. the operation causing her suc intense pain I administered chloroform to her, laying the piece of lin over her face with the anaesthetic on it while I went on with the reduction. The inverted mass was hard, with an irregular smooth surface; its upper part, however, felt quite regular and smooth, and was obviously due to partial inversion of the vagina. A finger passed between the inverted cervix and the vagina felt the remainder of the vagina as a tense, smooth mucous membrane. On attempting to reduce the mass by gentle pressure on the fundus upwards it became hard and contracted; so in spite of the collapsed condition of the patient I pushed the anaesthetic a little more and the hardness of the fundus decreased. Then, insertin the fingers of the left hand into the uninverted part of the vagina, the dorsal aspect of the hand being towards the sacrum, I was able by gentle presure upwards and forwards in the direction of the anterior abdom nal wall. at the same time steadying the inverted mass with the righ hand, also slightly compressing it so as to diminish its size with the right hand, to "tuck" in a fold of its posterior surface through the cervix. On the fold becoming bigger and deeper I exerted a little more pressure on the fundus, always keeping the direction of the genera. pressure exerted upwards and forwards, and the mass gradually disappeared through the vulva. Then, continuing to press the fundus upwards with the left hand and compressing it with the right through the anterior abdominal wall the whole slipped through my hands, the feeling being that of an india-rubber ball after being turned inside out "righting "itself.

On abdominal palpation, the fundus uteri was felt in the hypogastrium, and contraction took place almost immediately, after this there was litti or no haemorrhage. I then administered a hypodermic injection of ergotin with strychnine, and turned my attention to the general condition of the woman. She was in a truly desperate state, the pulse could hardly be felt and she was apparently almost lifeless. Hot blankets, hot bottles etc. were applied, friction to the extremities, and a large injection of hot galine solution into the rectum was made, about four pints in all being injected, about $\xi_{i j}$. of brandy was added to the solution. Almest immediately the pulse improved, was a little fuller in volume, but the collapse continued, however, with perseverance in the use of the restorative methods during the next few hours, the condition of the patient improved.

From that time the progress of the case was slow but satisfactory, the lochia during the first few days were a little offensive, and a little eleva tion of temperature occurred but on irrigation of the uterine cavity with a dolche of hot water and tincture of iodine, the temperature at once abated and the lochis became normal. A mixture of liq. ferri perchloridi and potassium chlorate, administered three-hourly, gave an excellent result in reducing the anaemia and pyrexia and improving the general condition of the patient. 
The previous confinements, five in number, had been normal, there was no rupture of the perineum, no displacement, nor prolapse before either pregnancy, and no history of fibroids.

This case presents several points of interest, showing the successful termination of an apparently hopeless casi: the cause of the inversion was probably the combination of excessive force on the abdomen, combined with traction on the cords during the attempt to deliver the placenta, both examples of the ignorance of the untrained widwife.

The method of reduction employed was one recommended in some textbooks - on attempting reduction by pressure on the fundus only, contraction tuok place, and reduction was thus impossible.

By the method of "tucking in" the posterior part of the inverted mass, through the cervix, together with the application of pressure in the proper direction, that is, upwards and forwards, combined with the firm compressing force exerted on the fundus, this force, by compression and thus emptying the uterine vessels, at the same time reducing the size of the inverted uterus, and controlling the haemorrhage, which from the vessels at the placental site was always very profuse, the operation of reduction was much simplified. The removal of the placenta, by reducing the size of the inverted mass, also assisted the operation materially.

The reports of the last few cases show that the prognosis, although very bad, is not, if immediate reduction is practised, and followed by great attention' to the urgent symptoms of collapse, quite so hopeless as mentioned in textbooks-the mortality given by some authors being about 75 to 85 per cent.

The value of saline solution injected into the rectum was very marked; a perceptible change took place in the volume of the pulse within a few minutes of the administration, absorption being very rapid after so severe a haemorrhage. The patient afterwards described her sensations when the injection had taken place, "as if something warm was going right through her veins."

The mixture administered of liq. ferri perchlor. and pot. chlor. I have found invaluable in cases of profound anaemia after haemorrhage, especially when complicated with elevation of temperature, the oxygenating power of the chlorate, together with the tonic action of the iron, being presumably both efficacious.

Lastly, the case is of interest as one of a few dangerous cases that one is called to in country practice, to follow the ignorant woman who is a self-styled "midwife" One is continually being called to such cases, often caused by the ignorance of these women. Often payment for one's services will be the last thing considered by the patient. One is obliged to go to the call to duty or run the risk of being considered by the general public, and even by one's neighbouring medical friends, as unworthy of the noble profession of which one is a member. Surely the time has come when two very important questions must be seriously taken up by the General Medical Council-those of the proper training and registration of midwives, and the question of State-aided midwifery.

\section{MEMORANDA:}

\section{MEDICAL，SURGICAL，OBSTETRICAL，THERA- PEUTICAL, PATHOLOGICAL, ETC.}

CASE OF SPONTANEOUS CRANIOTOMY.

MrS. A. B., aged 32, expected her first accouchement about December 24th, 1901. She had never had any illness beyond slight attacks of gout. The catamenia had always been regular. A month before the anticipated event there was haemorrhage per vaginam following a "very bad dream," the patient leaving her bed during sleep. The child was then living, and occupied the left dorso-anterior transverse position. The external os barely admitted the finger tip. The haemorrhage ceased within forty-eight hours.

On December 6th labour pains commenced at i i a.m., and at the time of my visit were occurring every thirty minutes. The position of the child was rectified without difficulty, and a firm binder was put on the abdomen. The nurse had ad- ministered a "good dose of castor oil" that morning. At 5 p.m. I attended in answer to a summons and found that the child was born. Pains came on stronger after applying the binder, the patient being kept upon her feet. The child (a female) was lying on its back with both legs and thighs flexed the feet resting against the mother's left buttock. The cord was almost black and without pulsation, but there was no discoloration about the body. The skin (outer) was torn off the right shoulder and arm, the front of the thorax and abdomen. The eyes and tongue were protruded; the head presenting the appearance of craniotomy forceps having been employed. The frontal bone was fractured, the fracture extending from above the left orbit to the right malar bone. The occipital was in two unequal portions. Several pieces of bone could be felt within the scalp, while the scalp itself was uninjured. 'The child was full term, though it weighed barely $6 \frac{1}{2} \mathrm{lb}$ There was some difficulty in removing the placenta, which was small but very thick, and contained several fibrous nodules, two of which were the size of a small marble. The patient lost very little, but was considerably exhausted for the first half-hour after parturition. Her pulse was good, but the temperature was only $97^{\circ}$. She has since done remarkably well.

With a view to advising in the event of a subsequent pregnancy, Dr. Arthur E. Giles kindly saw the patient with me. The result of his examination gives the following pelvic measurements: Super. il. ant., $9 \frac{3}{4}$; cristae ilii, II $\frac{3}{4}$; conj. ext.,

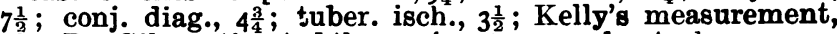
$4 \frac{3}{4}$. Dr. Giles estimated the conjugate vera about $4 \frac{1}{4}$.

It is evident, therefore, that pelvic deformity is not responsible for the crushing of the child's head. I can only suggest that the contractions were so powerful that the child was expelled with its head in hyperextension, the body passing into the pelvis before the head was completely clear. Even on this supposition it is difficult to account for the stripping of the skin off the child's right side. Any question of culpable violence could be entirely set aside. The case is an uncommon one, even if it is not unique.

Kensal Rise, w.

J. Cater, M.D.

\section{ANTISTREPTOCOCCUS SERUM IN PUERPERAL} FEVER.

ON February 22nd, 1902, I attended Mrs. L., a primipara, aged 24. Labour was natural, and without difficulty. Everything progressed favourably until the fourth day, when she had rigors, and her temperature rose to $105^{\circ}$, and the pulserate to 160 . There was no tenderness or distension of the abdomen. It was a case of puerperal fever without any symptoms save the high temperature and quick pulse. I put her on quinine, 5 gr. every three hours, and ordered intrauterine douches of perchloride of mercury, 1 in 2,000 .

For four days the temperature kept above $104^{\circ}$, and on one ccasion reached $105.6^{\circ}$ and the pulse ran from 140 to 160 . As the quinine was badly borne, I tried three ro-gr. doses of sodium salicylate. Although this caused profuse perspiration the temperature was unchanged. I then returned to the quinine, and gave her a single large dose (gr. xx) daily, and ordered cold sponging. The lochial discharge and milk secretion entirely ceased on the third day of the fever. On February 28th, the fourth day of the fever, as the patient was apparently sinking, I injected 1o c.cm. of Burroughs and Wellcome's antistreptococcus serum.

The following day the temperature was $103.4^{\circ}$, and the pulse 132. She looked slightly better, and her respiration was natural, whereas on the two preceding days it had been sighing in character. As this was the fifth day without any sleep, I gave her a drachm of paraldehyde, and she slept an hour towards morning. On March 2nd her temperature was $100.5^{\circ}$, and her pulse 144 but very weak-almost running. I injected one-fiftieth of a grain of strychnine, and put her on a mixture of tinct. digitalis, $m$ vijss; tinct. nuc.vomicae, $\mathrm{mv}$; and ammon. carb., gr.iij. She had improved somewhat at night, and I repeated the paraldehyde, but in divided doses, with an hour's interval. She slept well, and, after this, recovery was rapid and uneventful.

The patient took plenty of nourishment throughout-old whisky, milk, eggs, beef tea, chicken soup, etc.

I think there can be no doubt the antistreptococcus serum 